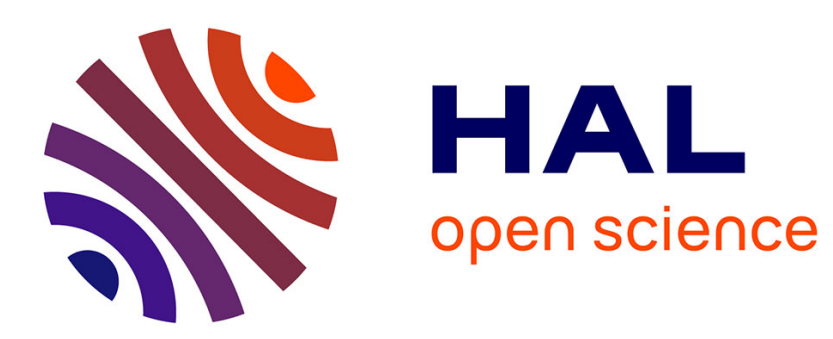

\title{
Manganese enhanced MRI in rat hippocampus: A correlative study with synchrotron X-ray microprobe.
}

\author{
Alexia Daoust, Emmanuel L. Barbier, Sylvain Bohic
}

\section{To cite this version:}

Alexia Daoust, Emmanuel L. Barbier, Sylvain Bohic. Manganese enhanced MRI in rat hippocampus: A correlative study with synchrotron X-ray microprobe.. NeuroImage, 2012, 64C, pp.10-18. 10.1016/j.neuroimage.2012.09.025 . inserm-00744958

\section{HAL Id: inserm-00744958 https://www.hal.inserm.fr/inserm-00744958}

Submitted on 24 Oct 2012

HAL is a multi-disciplinary open access archive for the deposit and dissemination of scientific research documents, whether they are published or not. The documents may come from teaching and research institutions in France or abroad, or from public or private research centers.
L'archive ouverte pluridisciplinaire HAL, est destinée au dépôt et à la diffusion de documents scientifiques de niveau recherche, publiés ou non, émanant des établissements d'enseignement et de recherche français ou étrangers, des laboratoires publics ou privés. 
Title

Distribution of Mn in rat hippocampus: A correlative study between MEMRI and Synchrotron X-Ray Microprobe

\section{Runnig title}

Mn Distribution in rat hippocampus

\section{Authors}

A.Daoust ${ }^{1,2}$, E. L. Barbier ${ }^{1,2}$, and S. Bohic ${ }^{1,2,3}$

${ }^{1}$ Inserm, U836, Grenoble, France

2Université Joseph Fourier, Grenoble Institut des Neurosciences, Grenoble, France

${ }^{3}$ European Synchrotron Radiation Facility (ESRF), Grenoble, France

Alexia DAOUST, daoustalexia@hotmail.fr

Sylvain BOHIC, bohic@esrf.fr

\section{Corresponding author}

Dr Emmanuel Luc BARBIER, PhD

Inserm unite 836

Chemin Fortuné Ferrini

BP 217 - CHU Grenoble

F-38043 Grenoble cedex, France

Tel: +33456520588

Fax: +33456520598

E-Mail: emmanuel.barbier@ujf-grenoble.fr

Abstract words count: 242

Text words count (text without references, tables, and legends): 4884

Tables: 2

Figures: 7

\section{Abbreviations}

MEMRI: Manganese enhance magnetic imaging

SR-XRF: Synchrotron X-ray fluorescence

\section{Key-words}

Manganese, MEMRI, X-ray synchrotron, MRI, hippocampus, rat 


\section{ABSTRACT}

Manganese enhanced MRI (MEMRI) offers many possibilities such as tract tracing and functional imaging in vivo. $\mathrm{Mn}$ is however neurotoxic and may induce symptoms similar to those associated with Parkinson's disease (manganism). The mechanisms of Mn-induced neurotoxicity are not clear. In this study, we combine synchrotron Xray fluorescence microprobe (SR-XRF) and MEMRI techniques to investigate spatial distribution of $\mathrm{Mn}$ within the rat hippocampus and how $\mathrm{Mn}$ interacts with $\mathrm{Ca}, \mathrm{Fe}$ and $\mathrm{Zn}$ at a cellular level. Images were acquired in the rat hippocampus $(\mathrm{n}=23)$ and using two injection routes: intra-cerebral $\left(\mathrm{MnCl}_{2}\right.$ : $\left.50 \mathrm{mM}, 10 \mu \mathrm{L}\right)$ and intra-peritoneal $\left(\mathrm{MnCl}_{2}: 100 \mathrm{mM}, 30 \mathrm{mg} / \mathrm{kg}\right)$. For both injection routes, $\mathrm{Mn}$ is found in dentate gyrus and in CA3: control: $2.5 \pm 1.6$, intra-peritoneal: $5.0 \pm 2.4$, and intra-cerebral: $25.1 \pm$ $9.2 \mu \mathrm{g} / \mathrm{g}$. Mn follows $\mathrm{Zn}$ distribution and has a negative impact on the total amount of $\mathrm{Zn}$ and Fe. The Mn-induced MRI contrast is well correlated with the total Mn amount measured with SR-XRF $\left(R^{2}=0.93 ; p<0.002\right)$. After intra-cerebral injection, the hippocampal fissure is found to accumulate a large amount of $\mathrm{Mn}$ and yields a hypointense MRI signal, which may be ascribed to a reduction in T2. This study shows that SR-XRF is well suited to investigate Mn distribution at a mesoscale and that $\mathrm{MRI}$ is sensitive to low $\mathrm{Mn}$ concentrations. As perturbations in metal homeostasis may alter brain function, the dose of injected Mn in MEMRI studies need to be carefully adjusted to obtain reliable functional information. 


\section{INTRODUCTION}

Manganese $(\mathrm{Mn})$ is an essential metal for brain functions (M Aschner et al. 2006a). It is a cofactor of several enzymes like the anti-oxidant enzyme superoxide dismutase or enzymes involved in neurotransmitter synthesis. Mn is also essential to process amino acid, lipids, proteins and metabolites such as dopamine and serotonin (Golub et al. 2005). Recently, Mn has become an important contrast agent used in magnetic resonance imaging (MRI). The technique is generally termed manganese enhance MRI (MEMRI) (Pautler 2004). Like gadolinium, Mn is paramagnetic and thus decreases $T_{1}$ and $T_{2}$ relaxation times. $\mathrm{Mn}^{2+}$ is a calcium analogue and is able to enter neurons through voltage dependant $\mathrm{Ca}^{2+}$ channels (Narita et al. 1990). It can then be transported along axon and can cross synapses (Pautler 2004). These properties make $\mathrm{Mn}^{2+}$ a unique contrast agent for tracing neuronal connections, functional studies or enhance brain cytoarchitecture (Pautler 2004). This technique has been used to study several neuronal pathologies like epilepsy (Hetherington 2009), stroke (Aoki et al. 2003), Alzheimer disease (K. D. B. Smith et al. 2007) and ageing (Minoshima \& Cross 2008).

Unfortunately, at high levels, $\mathrm{Mn}$ is toxic for the central nervous system. In human workers, Mn intoxication caused psychiatric and motor disorders. This disease, known as manganism, is characterized by Parkinson's like symptoms (Stredrick et al. 2004; Josephs et al. 2005). At a cellular level, an exposure to $\mathrm{Mn}$ induces mitochondrial disruption (Malecki 2001; Zwingmann et al. 2004; Malthankar et al. 2004) and modifies the homeostasis of other elements such as $\mathrm{Fe}^{2+/ 3+}$ and $\mathrm{Ca}^{2+}$ (Fitsanakis et al. 2010; Drapeau \& Nachshen 1984; Kwik-Uribe et al. 2003).

Given the known potential toxicity of $\mathrm{Mn}$ that can affect the brain structures under study and given the high interest of MEMRI to study neurodegenerative diseases, the 
question of the cellular distribution of $\mathrm{Mn}$ in the brain after a $\mathrm{Mn}$ injection should be addressed (Michael Aschner et al. 2007). Little work have been done to determine the $\mathrm{Mn}$ concentration in animal and human brains (endogenous or after $\mathrm{Mn}$ injection/inhalation) (Bonilla et al. 1982; J. F. Liu et al. 2000; Yasui et al. 1995; Tracqui et al. 1995) but to our knowledge the distribution of $\mathrm{Mn}$ ion at a cellular level has not been reported. Radioactive approaches using ${ }^{54} \mathrm{Mn}$ have a rather limited spatial resolution and do not provide Mn concentration (Gallez et al. 1997; Sloot \& Gramsbergen 1994). Classical microscopy approaches can displace the Mn ion (during steps such as rinsing) and others techniques like inductively coupled plasma mass spectrometry provide bulk $\mathrm{Mn}$ concentration in brain homogenates. After systemic injection, Mn accumulates particularly into the hippocampus, but also in several other brain structures, as described by Mok et al. (Mok et al. 2011). In this study, we use synchrotron X-ray fluorescence microprobe (SR-XRF) to map ex vivo the tissular distribution of $\mathrm{Mn}$ and other elements throughout the rat hippocampus. Data are compared to in vivo MEMRI to evaluate the possible influence of the injection route on the $\mathrm{Mn}$ distribution; systemic (intraperitoneal) and local (intrahippocampal) injections were investigated. 


\section{METHODS}

A total of twenty-three female 3-month-old Sprague-Dawley rats $(230 \pm 11 \mathrm{~g}$, Charles Rivers, France) were used. All experiments were approved by the local ethic committee and were in full compliance with the guidelines of the European community (EUVD 86/609/ EEC) for the care and use of the laboratory animals. Efforts were made to limit the number of animals used. All procedures were performed under isoflurane (IsoFlo, Axience, France) anesthesia (5\% for induction, maintenance under $2.5 \%$ ). Rectal temperature was monitored and maintained at approximately $37^{\circ} \mathrm{C}$ with a heating pad.

\section{Surgery and tracer injection}

Hydrated manganese chloride $\left(100 \mathrm{mM}, 30 \mathrm{mg} / \mathrm{Kg}, \mathrm{MnCl}_{2}-4 \mathrm{H}_{2} \mathrm{O}, \mathrm{M} 1787\right.$, Sigma-Aldrich, St Louis, MO, USA) was dissolved in $400 \mathrm{mM}$ bicine saline and $\mathrm{pH}$ was adjusted to 7.3 by adding $\mathrm{NaOH}$ that allow to reach physiological value of osmolarity (300 mOsm/L). Eventually, the $\mathrm{MnCl}_{2}$ solution was filtered through $0.2 \mu \mathrm{m}$ membranes. Two administration routes were considered:

Intraperitoneal (IP) injection rats received an injection of $\mathrm{MnCl}_{2}$ solution $(100 \mathrm{mM}, 30 \mathrm{mg} / \mathrm{kg})(\mathrm{n}=5)$ or vehicle solution $(n=5)$.

Intracerebral (IC) injection: $10 \mu \mathrm{L}$ of $\mathrm{MnCl}_{2}(50 \mathrm{mM})(\mathrm{n}=5)$ or $\mathrm{NaCl}(\mathrm{n}=5)$ were stereotaxically injected. The animals were placed in a stereotaxic frame and xylocain (Vétoquinol, France) was applied prior to the scalp incision. Bregma, the sagittal suture, and the surface of the brain were used as references for anteriorposterior $(-3.24 \mathrm{~mm})$, lateral $(-1.2 \mathrm{~mm})$ and ventral $(-4.0 \mathrm{~mm})$ coordinates, respectively. The skull was perforated over the dentate gyrus (DG) in the right dorsal hippocampus, based on stereotaxic coordinates (Paxinos \& Watson 2004) (Fig 1A). A 32 gauge $10 \mu \mathrm{l}$ Hamilton syringe needle was inserted $4.0 \mathrm{~mm}$ beneath the 
meninges surface and $\mathrm{MnCl}_{2}$ was pressure injected at a rate of $0.5 \mu \mathrm{L} / \mathrm{min}$. The syringe was left in place for 10 minutes and was retracted stepwise to prevent leakage of the tracer along the needle track. The wound was disinfected with Vetadine (Vétoquinol, France) and sutured. To control for the spatial accuracy of the IC injection, three additional animals were injected with Indian ink instead of $\mathrm{MnCl}_{2}$ solution and were subsequently euthanized for histological analysis (Fig 1B). Insert Figure 1

\section{In vivo MRI}

For both injection routes, $\mathrm{MRI}$ was performed $24 \mathrm{~h}$ after $\mathrm{MnCl}_{2}$ injection. The animals were placed in a dedicated cradle equipped with byte and ear bars. Temperature and breath rate were monitored during the acquisition. Experiments were carried out in a horizontal 7T MRI system (Avance III, Bruker, Ettlingen, Germany) using a surface/volume cross coil configuration. $T_{1}$-weighted images were obtained (TurboRare 3D, TR $=300 \mathrm{~ms}, \mathrm{TE}=12 \mathrm{~ms}$, matrix $128 \times 128 \times 64, \mathrm{FOV}=16$ x $16 \times 32 \mathrm{~mm}$, and voxel size $=0.125 \times 0.125 \times 0.5 \mathrm{~mm})$. The acquisition duration was 14 min. A $T_{1}$ map, at a lower spatial resolution was obtained using a saturation recovery approach (Spin-Echo, $18 \mathrm{TR}$, in the range of [30-3750] ms, TE $=7.8 \mathrm{~ms}$, matrix $128 \times 128, \mathrm{FOV}=28 \times 28 \mathrm{~mm}$, slice thickness $=1 \mathrm{~mm}, 1$ slice, and voxel size $=$ $0.22 \times 0.22 \mathrm{~mm})$. The acquisition duration was $17 \mathrm{~min}$.

\section{MRI data analysis}

MRI data were analyzed using software developed in the Matlab environment (Mathworks, Natick, MA, USA). $T_{1}$ maps were derived by fitting to the saturationrevovery data a two-parameter monoexponential recovery function using a non-linear fitting algorithm. $T_{1}$ values were eventually converted to $\mathrm{Mn}$ concentrations as described in Silva et al. 2004 and using a Mn relaxivity $r_{1}$ of $6.7 \mathrm{mMol}^{-1} . \mathrm{s}^{-1} . \mathrm{Kg}$. 
Four regions of interest (ROI) were manually drawn: the background noise and three ROIs in the hemisphere contralateral to the injection site: CA3/DG, CA1/2, and $\mathrm{HF}$ in the hippocampus. The signal to noise ratio (SNR) in CA3/DG, CA1/2, and HF was computed. The MEMRI contrast for a ROI was obtained by computing the difference in SNR measured with and without Mn.

\section{Histology and SR-XRF imaging}

After MRI, all animals were euthanized with a lethal dose of pentobarbital transcardially $(250 \mathrm{mg} / \mathrm{kg}$, Doléthal, Vétoquinol, France). The brain was quickly removed from the skull, frozen in $-40^{\circ} \mathrm{C}$ isopentane and stored at $-80{ }^{\circ} \mathrm{C}$. Serial $10-$ and $20 \mu \mathrm{m}$-thick coronal sections of the dorsal hippocampus were obtained on a cryostat (Microm Cryo-Star HM560 Cryostat). The $10 \mu \mathrm{m}$-thick sections were placed on glass slides and stored at $-20^{\circ} \mathrm{C}$ for further histological analyses. The $20 \mu \mathrm{m}$-thick sections were mounted on laser micro-dissection slides (MMI Molecular Machines and Industries, Zurich, Switzerland) and stored at room temperature in sealed environment prior to synchrotron analysis.

\section{SR-XRF data analysis}

Experiments were carried out at the European Synchrotron Radiation Facility (ESRF) ID22 microprobe end-station (Bohic et al. 2012). The X-ray energy was set to 14.4 keV using a Si (111) double crystal fixed-exit monochromator $\left(\Delta E / E \approx 10^{-4}\right)$. The high-intensity focused X-ray beam that impinges onto the sample causes elements to fluoresce with a characteristic energy signature. X-ray fluorescence analysis allow quantitative multielemental analysis, imaging capabilities with little radiation damage. The X-ray beam was focused to a $5 \times 15 \mu \mathrm{m}^{2}$ spot (vertical $\times$ horizontal) with a Kirkpatrick-Baez (KB) mirror system and we used an integration time of $7 \mathrm{~s} /$ pixel. The resulting elemental images were normalized to the incident flux. X-ray 
fluorescence spectra were evaluated with PyMca software that allows calculation of elemental concentrations within a sample from the registered $\mathrm{X}$-ray fluorescence spectra (Sole et al. 2007). A NIST standards reference materials SRM1577b bovine liver (NIST, Gaithersburg, MD) was used to calibrate experimental parameters. The concentration of $\mathrm{P}, \mathrm{S}, \mathrm{K}, \mathrm{Ca}, \mathrm{Fe}, \mathrm{Cu}, \mathrm{Zn}$ and $\mathrm{Mn}$ were calculated assuming a tissue section of $20 \mu \mathrm{m}$ and a matrix density of $1 \mathrm{~g} / \mathrm{cm}^{3}$. The rat tissue cryosections met the criteria of "thin samples" and did not require matrix corrections. Synchrotron elemental maps were manually aligned over a rat brain atlas (Paxinos \& Watson 2004). Due to time constraints, two types of field of view (FOV) were used: a large FOV covering the entire hippocampus or a reduced FOV centered over the CA3/DG area. Concentrations, expressed in ppm ( $\mu \mathrm{g} / \mathrm{g}$ dry weight), were measured from two manually selected zones: the CA3/DG (Table 1) and the hippocampal fissure (HF) (Table 2) as shown from the $\mathrm{Zn}$ distribution map (Fig 2). The concentration in $\mathrm{mM}$ were derived from the concentration (mass fraction dry weight), assuming a matrix density equal to that of water. Sulfur was used as proxy for proteins (de Jonge et al. 2010) thus all elemental concentrations were normalized by that of $S$ to correct for possible variation in slice thickness or in protein amount between samples.

Due to limited access to SR-XRF imaging (about seven facilities worldwide capable of reaching the desired X-ray flux) and to the long scan time per sample (about 7 hours), only a fraction of the animals imaged with MRI were analyzed. The number of SR-XRF imaged samples is mentioned in the corresponding results.

Insert Figure 2

\section{Histological analysis}

The sections adjacent to those analyzed by SR-XRF were used for immunofluorescence. Sections were fixed with PFA $4 \%$, rinsed three times for 10 
minutes each in a solution of $1 \mathrm{X}$ phosphate buffer saline (PBS) and Tween $0.1 \%$, and incubated over night at $4{ }^{\circ} \mathrm{C}$ in the blocking solution (bovine serum albumine (BSA) $3 \%$, tween $0.1 \%$ in PBS 1X) containing two primary antibodies: mouse antiNeuN (monoclonal anti-neuronal nuclei, IgG1, $1 \mathrm{mg} / \mathrm{ml}$, Chemicon International) and rabbit anti-GFAP (polyclonal anti-glial fibrillary acidic protein, IgG fraction of antiserum, Dako) diluted at 1:1000. After rinsing, the sections were incubated in the dark for 60 minutes at room temperature in the blocking solution containing the secondary antibodies: anti-mouse Alexa 488 (Alexa Fuor® 488 donkey, $\lg G(\mathrm{H}+\mathrm{L})$, Molecular Probes, Invitrogen) and anti-rabbit TRITC (TRITC-conjugated IgG $(\mathrm{H}+\mathrm{L})$ monkey, Jackson ImmunoResearch, West Grove, USA) diluted at 1:500 to a working concentration of $4 \mu \mathrm{g} / \mathrm{mL}$. After rinsing, the sections were mounted in a solution of Hoechst $(33258,10 \mu \mathrm{g} / \mathrm{mL}$ ) to label cell nuclei and Fluor guard mounting medium for fluorescence (Scytek, Logan, USA).

\section{Statistical analysis}

Results are expressed as mean \pm standard deviation (SD). The following comparisons were made:

- The MEMRI contrast between IC and IP injected animals was compared using an unpaired t-test.

- The elemental concentrations between control, IC injected and IP injected animals were compared using an unpaired t-test.

To evaluate whether the elemental concentration of Mn assessed by SR-XRF is a predictor of the MEMRI SNR, the Pearson correlation coefficient was computed. A $p$ value $<0.05$ was considered as significant. 


\section{RESULTS}

\section{Distribution of Mn in the rat hippocampus after MEMRI}

Twenty-four hours after IP injection of $\mathrm{MnCl}_{2}, \mathrm{MRI}$ images revealed an excellent cytoarchitectonic contrast in regions such as the hippocampus (CA3/DG and CA1/2), pituitary gland, cerebellum and olfactory bulbs, as previously reported (Aoki et al. 2004) Fig 3.

Insert Figure 3

The IC injection of Mn into the right DG increases the MRI contrast in the brain and particularly in the hippocampus (Watanabe et al. 2004). The MEMRI contrasts in the hippocampus, observed $24 \mathrm{~h}$ after $\mathrm{MnCl}_{2}$ injection are, $11.1 \pm 3.8$ in DG/CA3, $9.5 \pm$ 2.4 in $\mathrm{CA} 1 / 2$, and $6.9 \pm 2.1 \mathrm{in} \mathrm{HF}$ after IC injection of $\mathrm{Mn}$ and $6.0 \pm 2.1$ in DG/CA3, $5.0 \pm 1.8$ in $\mathrm{CA} 1 / 2$, and $4.0 \pm 1.6$ in $\mathrm{HF}$ after IP injection. Note that the variability on MEMRI contrast is below $20 \%$ across all areas and injection routes, suggesting a good reproducibility (Fig 4).

After IP injection, the T1-weighted SNR is significantly enhanced in all ROIs (81 \% in CA3/DG, $69 \%$ in CA1/2, and $56 \%$ in HF). The SNR is further enhanced after IC injection (242 \% in CA3/DG, $204 \%$ in CA1/2,and $157 \%$ in HF) (Fig 4). Overall, the largest MEMRI contrast is in the DG/CA3 for both injection routes.

Insert Figure 4

The MEMRI images obtained for control, IP and IC injected animals and the $\mathrm{Mn}, \mathrm{Ca}, \mathrm{Zn}$ and Fe SR-XRF maps from the corresponding cryosections are shown in Fig. $6 \mathrm{~A}$ and Fig. 6B, respectively. In the control group, the SR-XRF signal of $\mathrm{Mn}$ is barely observable and is mainly located within the DG region (Fig 6B). The presence of $\mathrm{Cr}$ or $\mathrm{Ni}$ associated to some $\mathrm{Mn}$ hotspots (data not shown) allows assigning them to unavoidable contaminants that originated from the sectioning process. A faint 
increase in the Mn signal is observed in the hippocampus $24 \mathrm{~h}$ after IP injection. The highest levels of $\mathrm{Mn}$ are found in the CA3/DG area. After IC injection, Mn is also found in $C A 3 / D G$ and in the HF.

Insert Figure 5

The CA3/DG is mainly composed of neuronal cellular bodies while the HF is composed of astrocytes (Fig 5). Note that the IC injection of Mn led to a hyper GFAPdensity in the hilus of DG and in the HF. The $\mathrm{Zn}$ distribution follows the hippocampal mossy fibers, in agreement with literature (Haug 1967). 24-h after injection, the SRXRF images suggest a Mn localization within the hilus (polymorphic cell layer) and along the axons from granule cells of the DG (mossy fibers) up to the pyramidal cells in stratum lucidum. The high load of Mn within the HF for IC animals appears to be buffered by astrocytes. A higher level of $\mathrm{Mn}$ is also observed along mossy fibers from the hilus to the CA3 when compared to IP injected animals. All these results are in line with the MRI observations of Aoki et al. (Aoki et al. 2004). Despite the good spatial resolution of SR-XRF technique it is still difficult to ascertain the exact cellular targets of Mn after MEMRI when compared to immunofluorescence images.

Insert Figure 6

\section{Mn concentration in the hippocampus assessed by SR-XRF and by MRI}

The Mn concentrations in CA3/DG estimated by SR-XRF are $2.5 \pm 1.6 \mu \mathrm{g} / \mathrm{g}$ (0.046 mM) for the control group, $5.0 \pm 2.4 \mu \mathrm{g} / \mathrm{g}(0.091 \mathrm{mM})$ for the IP group, and $25.1 \pm 9.2 \mu \mathrm{g} / \mathrm{g}(0.458 \mathrm{mM})$ for the IC group. A very high Mn concentration of $105.0 \pm$ $28.3 \mu \mathrm{g} / \mathrm{g}(1.913 \mathrm{mM})$ is found in the HF for the IC group while it remains between $2.0 \pm 0.9$ to $3.0 \pm 2.7 \mu \mathrm{g} / \mathrm{g}(0.036-0.055 \mathrm{mM})$ for the control and IP groups, respectively (Tables 1 and 2 ). 
Using MRI, a higher Mn concentration is found in the injected CA3/DG area $(0.55 \pm$ $0.06 \mathrm{mM})$ than in the corresponding contralateral area $(0.30 \pm 0.10 \mathrm{mM})$. The same is observed for the CA1/2 area (injected side: $0.55 \pm 0.01 \mathrm{mM}$; contralateral side: $0.35 \pm$ $0.13)$. In the HF, the Mn concentration is $0.48 \pm 0.01 \mathrm{mM}$ in the injected side and 0.37 $\pm 0.14 \mathrm{mM}$ in the contralateral side. For control rats, there is a low Mn concentration in all areas: $0.03 \pm 0.01 \mathrm{mM}$ in the CA3/DG, $0.03 \pm 0.01 \mathrm{mM}$ in the $\mathrm{CA} 1 / 2$, and $0.03 \pm$ $0.01 \mathrm{mM}$ in the HF for both hemispheres (data not shown).

\section{Zinc, calcium and iron distribution and concentration in the hippocampus after MEMRI}

As shown in Figure 6, the $\mathrm{Zn}$ distribution revealed by SR-XRF microscopy follows the hippocampal mossy fibers which project from dentate granule cells to the hilus and to the CA3. The iron elemental map shows large hotspots, which can be assigned to contaminants from sectioning and mainly from residual blood (unperfused animals). If one excludes these hotspots, iron is found to follows the cell body layers of both the DG and the Ammon's Horn (Figure 6B). The calcium distribution within the hippocampus cryosections is diffuse and at a low level.

The amounts of $\mathrm{Zn}(46.9 \pm 4.4 \mu \mathrm{g} / \mathrm{g})$ and Fe $(23.8 \pm 5.9 \mu \mathrm{g} / \mathrm{g})$ in IP injected animals are significantly decreased compared to that of control animals (55.0 \pm 8.6 $\mu \mathrm{g} / \mathrm{g}$ and $36.4 \pm 13.7 \mu \mathrm{g} / \mathrm{g}$, respectively) in the CA3/DG areas (Table 1). The IP injection of $\mathrm{MnCl}_{2}$ does not modify the amount of metals in the hippocampal fissure (Table 2). After IC injection of $\mathrm{MnCl}_{2}$, the amounts of $\mathrm{Zn}(40.5 \pm 4.6 \mu \mathrm{g} / \mathrm{g})$ and $\mathrm{Fe}$ $(20.6 \pm 1.9 \mu \mathrm{g} / \mathrm{g})$ in the CA3/DG are also smaller than in control animals. In the HF, the variability on the results was higher due the small number of samples. The concentration of the other elements was found similar after IP Mn injection in the HF except for a non significant decrease in Fe. Elements are more affected by IC 
injection of Mn compared to control $(105 \pm 28.3 \mu \mathrm{g} / \mathrm{g}$ and $2.0 \pm 0.9 \mu \mathrm{g} / \mathrm{g}$ respectively for Mn concentration) in the CA3 and DG (Table 1). A similar decrease in $\mathrm{Zn}$ and $\mathrm{Fe}$ is observed in the HF (Table 2).

Insert Figure 7 


\section{DISCUSSION}

In this study, we characterize the hippocampal distribution of Mn after IP and IC administrations using a unique combination of MR and SR-XRF imaging. After IP injection, the distribution of total $\mathrm{Mn}$ in the hippocampus as determined by SR-XRF is in good agreement with the signal enhancement observed with $\mathrm{T}_{1}$-based MRI. After IC injection, we show using SR-XRF that astrocytes found in the HF store massively Mn while a hypointense signal is found with MRI. For both injection routes, SR-XRF also indicates that $\mathrm{Mn}$ has a negative impact on the total amount of $\mathrm{Zn}$ and $\mathrm{Fe}$ in the hippocampus in our experimental conditions.

Manganese is an essential element tightly regulated and found at low level in tissues like the central nervous system (Michael Aschner \& Dorman 2006). Bonilla et al..reported a Mn concentration in the range of 1 to $4.2 \mu \mathrm{g} / \mathrm{g}$ dry weight for the human hippocampus (Bonilla et al. 1982). In rat hippocampus, the physiological Mn concentration estimated by SR-XRF was $2.5 \pm 1.6 \mu \mathrm{g} / \mathrm{g}$ dry weight in the CA3/DG area and $2.0 \pm 0.9 \mu \mathrm{g} / \mathrm{g}$ dry weight in the HF. Experimental data on the $\mathrm{Mn}$ concentration within rat hippocampus are scarce. Kemp and Dansher reported elemental concentrations in 1-mm thick sections of non-fixed hippocampus tissue of $3.8 \mu \mathrm{g} / \mathrm{g}$ dry weight using particle-induced X-ray emission spectroscopy (Kemp \& Danscher 1979). ICP-MS bulk measurements on excised entire hippocampus show a Mn content between 0.6 and $0.84 \mu \mathrm{g} / \mathrm{g}$ wet weight (Tarohda et al. 2005; Bock et al. 2008a). These values can be converted to dry weight assuming a $80 \%$ water content of the brain tissue (Barbier et al. 2005). This leads to Mn concentrations in the range of 3 to $4.2 \mu \mathrm{g} / \mathrm{g}$ dry weight. These measurements, obtained on the whole hippocampus, are in good agreement with our results on CA3/DG and HF regions. 
After Mn injection, both MRI and SR-XRF show an increased Mn content in the hippocampus. From a quantitative point of view, a good correlation is obtained between the increase in $T_{1} W-S N R$ and $M n$ concentrations determined by SR-XRF in the CA3/DG area $\left(r^{2}=0.93 ; p<0.002\right.$; Fig 7$)$. The IP injection route yields an increased $\mathrm{Mn}$ content within the CA3/DG area $\left(\mathrm{T}_{1} \mathrm{~W}-\mathrm{SNR}:+81 \%\right.$, $[\mathrm{Mn}]=5.0 \pm 2.4$ $\mu \mathrm{g} / \mathrm{g})$. Mn content is further increased after IC injection $\left(\mathrm{T}_{1} \mathrm{~W}-\mathrm{SNR}:+242 \%,[\mathrm{Mn}]=\right.$ $25.1 \pm 9.2 \mu \mathrm{g} / \mathrm{g})$. Bock et al. measured Mn concentration with ICP-MS in rat hippocampus homogenates after four IV injections of $\mathrm{MnCl}_{2}$ (30 mg/kg, $40 \mathrm{mM}$ ) (Bock et al. 2008b). They reported a manganese concentration of $1.8 \pm 0.3 \mu \mathrm{g} / \mathrm{g}$ wet weight that roughly corresponds to $9.0 \pm 1.5 \mu \mathrm{g} / \mathrm{g}$ dry weight, in line with our data obtained after a single IP injection (30 mg/kg, $100 \mathrm{mM})$.

Although MEMRI is a unique method for longitudinal in vivo imaging of functional and neuronal connectivity (for review see Koretsky \& Silva 2004), it requires an intracerebral injection. We report for the first time spatial distribution of $\mathrm{Mn}$ and associated concentration after intra-hippocampal injection of $\mathrm{MnCl}_{2}$. The observed 52-fold increase in Mn concentration within the HF has never been reported. However, after a careful look to MEMRI images, the enhanced HF regions depicted by SR-XRF corresponds to a hyposignal on the $\mathrm{T}_{1} \mathrm{~W}$ MR image. This may be ascribed to the reduction in $T_{2}$ due to the high concentration of $M n$, the $T_{1} w$ sequence used in this study had an echo-time of $12 \mathrm{~ms}$ and was thus sensitive to reduction in $\mathrm{T}_{2}$.

The use of $T_{1}$ and $T_{2}$ maps to further quantify the Mn concentration in the HF yielded values between 0.26 and $1.2 \mathrm{mM}$ (using a relaxivity for $\mathrm{Mn}$ of $6.7 \mathrm{mMol}^{-1} . \mathrm{s}^{-1} . \mathrm{Kg}$.) compared to $105.0 \mu \mathrm{g} / \mathrm{g}$ dry weigh after an IC injection (i.e. $1.91 \mathrm{mM}$ ) as determined by SR-XRF. This large interval is due to large uncertainty on the Mn relaxivity in tissues (Silva et al. 2004). 
Recently, Schmitt et al. shows the unidirectional blood-to-CSF transport of Mn across the choroid plexuses linking the systemic exposure to manganese with the spreading pattern of manganese accumulation observed in brain imaging (Schmitt et al. 2011). Our work presented here shows quantitatively that manganese uptake in hippocampus, although several times higher than physiological level, remains at a low level in the low tenth ppm range and indicate a relatively high sensitivity of MEMRI. The $\mathrm{Mn}^{2+}$ ions, known to enter neuronal cells, can target intracellular compartments and bind to proteins. This behavior may contribute to enhanced intracellular proton relaxivity (Nordhøy et al. 2003) and thereby to enhanced MR sensitivity.

From a spatial point of view, the two techniques yield comparable contours for the enhanced areas, despite the much lower spatial resolution of MRI. After IP injection, the SR-XRF images show a diffuse Mn distribution in the hilus of the DG and follows axons projection (mossy fibers) to the CA3. These distributions of Mn parallel those of $\mathrm{Zn}$, as depicted by SR-XRF. Furthermore, the free pool of $\mathrm{Zn}^{2+}$ in hippocampus is localized in the synaptic vesicles of mossy fibers (MF) which project to the DG (Frederickson 1989). After IP injection, the level of Mn is higher in DG/CA3 area than in the HF. Moreover, there seems to be a decreasing Mn concentration gradient from DG to CA3. This is consistent with an arrival of $\mathrm{Mn}$ via the ventricles (Aoki et al. 2004) as the DG is located near the third ventricle. After IC injection, Mn diffuses through the interstitium and is thus available to a larger number of hippocampic structures. The DG and CA1 regions are separated by GFAP-positive cells that populate the HF where the hippocampal blood vessels penetrate the hippocampus (Sievers et al. 1992). This is consistent with the higher amount of Mn found in the HF compared to values in the CA3/DG and also with the previously reported ability of 
astrocytes to accumulate $\mathrm{Mn}$ and detoxify brain (Vezér et al. 2007). We evidenced hyper GFAP-density (astrogliosis) in the HF after IC injection and in the hilus of DG as previously reported (Vezér et al. 2007). Importantly, in our experimental conditions, the levels of $\mathrm{Mn}$ were not high enough to induce neuronal death. Although it appears not detrimental to the $\mathrm{Mn}^{2+}$ enhanced cytoarchitecture, it may compromise the use of MEMRI for tract tracing or functional imaging.

There are some limitations in comparing the results from the two techniques used in this study. With MRI, changes in Mn concentration were derived from $\mathrm{T}_{1}$-weighted signals. These changes are not linearly related to the Mn concentration and depends on the Mn relaxivity in tissue which is not clearly determined (Silva et al. 2004). Indeed, the relaxivity is subject to change that is dependent on the molecular form of $\mathrm{Mn}$ in tissues that makes difficult quantification of the Mn content. Conversely, the SR-XRF signal can be considered as linearly dependent on the absolute number of analyte atoms; inter-element matrix effects (self-absorption, enhancement or secondary emission) being neglected in the case of very thin tissues sections used in the present study (Janssens et al. 2000) (rajouter Bohic et al. 2001 Applied Physic Letters). Moreover, $\mathrm{MRI}$ is sensitive to free $\mathrm{Mn}\left(\mathrm{Mn}^{2+}\right.$ or $\left.\mathrm{Mn}^{3+}\right)$, (Sotak et al. 2008; Silva et al. 2004) only while SR-XRF yields the total Mn content. MRI signals were collected in vivo from a 1-mm thick slice while a dried, 20- $\mu$ m thick, cryosection was observed with SR-XRF. This large volume probe by MRI also explains the very good sensitivity of the MEMRI. The reproducibility of the two techniques was also different. The variability on the T1w contrast $24 \mathrm{~h}$ after Mn injection was between 13 and $20 \%$ for the three hippocampal areas, suggesting a good reproducibility of the MEMRI protocol. For the SR-XRF, the variability on the Mn concentration was between 27 and $90 \%$. These large variations may be ascribed to various experimental factors. 
First, we assume a constant density and thickness for the brain tissue but this areal mass may vary locally. Second, and most importantly, the small number of animals analyzed with SR-XRF contributes to these large statistical variations. However, given the extremely high sensitivity and specificity of synchrotron measurements, as well as practical constraints on access to these large scale facilities, sample numbers in synchrotron studies typically range from one to five tissues sections per cases.

Manganese is known to have high affinity for $\mathrm{Ca}$, iron and zinc (Michael Aschner \& Dorman 2006; M Aschner et al. 2006b). $\mathrm{Mn}^{2+}$ ions is a Ca analog that enter excitable cells through voltage-gated $\mathrm{Ca}^{2+}$ channels (Narita et al. 1990) and is expected to alter Ca homeostasis. Recently, Eschenko et al. showed that systemic administration of $\mathrm{MnCl}_{2}$ in MEMRI had no behavioral, electrophysiological and histopathological consequences on rat brain (Eschenko et al. 2010). This is further supported by our findings showing that the total amount of $\mathrm{Ca}$ (Ca-bound) was neither modified by the IP injection nor the IC injection. Still, SR-XRF yields the total amount of $\mathrm{Ca}$ at a single time point $(24 \mathrm{~h})$ and it does not rule out local and/or transient modifications of the free pool of $\mathrm{Ca}^{2+}$.

As mentioned above, the Mn distribution follows that of $Z n$, a reporter of mossy fibers (Nairismägi et al. 2006). High content and expression of Zinc transporter 3 were reported in the hippocampus but also in the cortex (Shen et al. 2007). It is tempting to speculate that Zinc transporter 3 could play a role in Mn uptake in the hippocampus and that $\mathrm{Mn}$ could compete with $\mathrm{Zn}$ being sequestered in $\mathrm{Zn}^{2+}$ synaptic vesicles. To our knowledge, a competition between $\mathrm{Zn}$ and $\mathrm{Mn}$ for these transporters has not been reported. Furthermore, the spatial resolution of the SR-XRF used in this study is not appropriate to identify the potentially cellular and sub-cellular targets of $\mathrm{Mn}$ after a 
systemic administration. Further dedicated studies combining electron microscopy and synchrotron nanoprobe will be necessary to identify the Mn targets at the ultrastructural level.

Iron and manganese are chemically and biochemically similar. Mn can thus potentially interact directly with $\mathrm{Fe}$ at the cellular and subcellular levels and disrupts Fe homeostasis (M Aschner 2000). We found a decrease in the total amount of $\mathrm{Fe}$ both after an IP and and IC injections of Mn. Chua et al. reported that Fe and Mn are both transported by transferrine (Tfr) transporters (Chua \& Morgan 1996). In vitro, an excess of $\mathrm{Mn}$ decreases the activity of aconitase, a regulative protein of iron equilibrium. This mimics a Fe deficiency via an increased Tfr expression (W. Zheng \& Zhao 2001; Kwik-Uribe et al. 2003). Iron may compete with Mn for binding site of iron-regulatory protein that are widely expressed in the hippocampus (Huang et al. 2006).

In conclusion, our findings show a strong accumulation of $\mathrm{Mn}$ in the HF after IC injection of $\mathrm{Mn}$, reflecting its accumulation in astrocytes. Both $\mathrm{Mn}$ injection routes induce a decrease in Fe and $\mathrm{Zn}$ suggesting a competition between these specific metal ions. Moreover, the total Ca detected using SR-XRF was not disturbed after a $100 \mathrm{mM}$ intracerebral injection of $\mathrm{Mn}$ (which does not rule out local disturbances for free $\mathrm{Ca}^{2+}$ pools). These results show that $\mathrm{Mn}$, and thus MEMRI, can disturb metal homeostasis and may alter brain function. The combined use of SR-XRF and MEMRI technique allow a better understanding of the distribution of Mn within the hippocampus after IP or IC injections of $\mathrm{MnCl}_{2}$. The $\mathrm{Mn}$ concentration as determined by SR-XRF supports a high sensitivity of the MEMRI that might be explained by the intracellular localization of $\mathrm{Mn}^{2+}$ and possibly bound to proteins or metabolites. To 
better understand the mechanisms of Mn accumulation and transport, further studies should investigate the impact of $\mathrm{Mn}$ at a subcellular level.

\section{ACKNOWLEDGEMENTS}

The authors acknowledge the support of the MRI Facility of Grenoble, The ESRF Facility (Rémy Tucoulou, Murielle Salomé from beamline ID22 and ID21), and the HASYLAB Facility (Karen Rickers-Apple for beamline L) are acknowledged for provision of synchrotron radiation beamtime (respectively, exp. MD-458, MD-548, and exp. I-20110614 EC). AD received a stipend from the Région Rhône-Alpes Cluster HVN. 


\section{REFERENCES}

Aoki, I. et al., 2003. Detection of the anoxic depolarization of focal ischemia using manganese-enhanced MRI. Magnetic Resonance in Medicine: Official Journal of the Society of Magnetic Resonance in Medicine / Society of Magnetic Resonance in Medicine, 50(1), p.7-12.

Aoki, I. et al., 2004. In vivo detection of neuroarchitecture in the rodent brain using manganese-enhanced MRI. NeuroImage, 22(3), p.1046-1059.

Aschner, M, 2000. Manganese: brain transport and emerging research needs. Environmental Health Perspectives, 108(Suppl 3), p.429-432.

Aschner, M, Lukey, B. \& Tremblay, A., 2006a. The Manganese Health Research Program (MHRP): status report and future research needs and directions. Neurotoxicology, 27(5), p.733-736.

Aschner, M, Lukey, B. \& Tremblay, A., 2006b. The Manganese Health Research Program (MHRP): status report and future research needs and directions. Neurotoxicology, 27(5), p.733-736.

Aschner, Michael et al., 2007. Manganese: recent advances in understanding its transport and neurotoxicity. Toxicology and Applied Pharmacology, 221(2), p.131147.

Aschner, Michael \& Dorman, D.C., 2006. Manganese: pharmacokinetics and molecular mechanisms of brain uptake. Toxicological reviews, 25(3), p.147-154.

Barbier, E.L. et al., 2005. Focal brain ischemia in rat: acute changes in brain tissue T1 reflect acute increase in brain tissue water content. NMR in Biomedicine, 18(8), p.499-506.

Bock, N.A. et al., 2008a. Cerebrospinal fluid to brain transport of manganese in a nonhuman primate revealed by MRI. Brain Research, 1198(0), p.160-170.

Bock, N.A. et al., 2008b. Cerebrospinal fluid to brain transport of manganese in a nonhuman primate revealed by MRI. Brain Research, 1198, p.160-170.

Bohic, S. et al., 2012. Biomedical applications of the ESRF synchrotron-based microspectroscopy platform. Journal of Structural Biology, 177(2), p.248-258.

Bonilla, E. et al., 1982. The regional distribution of manganese in the normal human brain. Neurochemical Research, 7(2), p.221-227.

Chua, A.C. \& Morgan, E.H., 1996. Effects of iron deficiency and iron overload on manganese uptake and deposition in the brain and other organs of the rat. Biological trace element research, 55(1-2), p.39-54.

Drapeau, P. \& Nachshen, D.A., 1984. Manganese fluxes and manganese-dependent neurotransmitter release in presynaptic nerve endings isolated from rat brain. The Journal of Physiology, 348, p.493-510. 
Eschenko, O. et al., 2010. Behavioral, electrophysiological and histopathological consequences of systemic manganese administration in MEMRI. Magnetic Resonance Imaging, 28(8), p.1165-1174.

Fitsanakis, V.A. et al., 2010. Manganese (Mn) and iron (Fe): interdependency of transport and regulation. Neurotoxicity Research, 18(2), p.124-131.

Frederickson, C.J., 1989. Neurobiology of zinc and zinc-containing neurons. International Review of Neurobiology, 31, p.145-238.

Gallez, B. et al., 1997. Accumulation of manganese in the brain of mice after intravenous injection of manganese-based contrast agents. Chemical Research in Toxicology, 10(4), p.360-363.

Golub, M.S. et al., 2005. Neurobehavioral evaluation of rhesus monkey infants fed cow's milk formula, soy formula, or soy formula with added manganese. Neurotoxicology and Teratology, 27(4), p.615-627.

Haug, F.M., 1967. Electron microscopical localization of the zinc in hippocampal mossy fibre synapses by a modified sulfide silver procedure. Histochemie. Histochemistry. Histochimie, 8(4), p.355-368.

Hetherington, H., 2009. Novel approaches to imaging epilepsy by MRI. Future Neurology, 4(3), p.295-304.

Huang, E. et al., 2006. Upregulation of iron regulatory proteins and divalent metal transporter-1 isoforms in the rat hippocampus after kainate induced neuronal injury. Experimental brain research. Experimentelle Hirnforschung. Expérimentation cérébrale, 170(3), p.376-386.

Janssens, K.H.A., Adams, F.C.V. \& Rindby, A., 2000. Evaluation and calibration of micro-XRF data. In Microscopic X-ray fluorescence analysis. Chichester, p. 155207.

de Jonge, M.D. et al., 2010. Quantitative 3D elemental microtomography of Cyclotella meneghiniana at $400-\mathrm{nm}$ resolution. Proceedings of the National Academy of Sciences of the United States of America, 107(36), p.15676-15680.

Josephs, K.A. et al., 2005. Neurologic manifestations in welders with pallidal MRI T1 hyperintensity. Neurology, 64(12), p.2033 -2039.

Kemp, K. \& Danscher, G., 1979. Multi-element analysis of the rat hippocampus by proton induced X-ray emission spectroscopy (phosphorus, sulphur, chlorine, potassium, calcium, iron, zinc, copper, lead, bromine, and rubidium). Histochemistry, 59(3), p.167-176.

Koretsky, A.P. \& Silva, A.C., 2004. Manganese-enhanced magnetic resonance imaging (MEMRI). NMR in Biomedicine, 17(8), p.527-531.

Kwik-Uribe, C.L. et al., 2003. Alterations in cellular IRP-dependent iron regulation by in vitro manganese exposure in undifferentiated PC12 cells. Brain Research, 973(1), p.1-15. 
Liu, J.F., Jiang, G.B. \& Feng, Y.D., 2000. Flow injection spectrophotometric determination of copper, iron, manganese, and zinc in animal feeds using a common manifold. Journal of AOAC International, 83(6), p.1293-1298.

Malecki, E.A., 2001. Manganese toxicity is associated with mitochondrial dysfunction and DNA fragmentation in rat primary striatal neurons. Brain Research Bulletin, 55(2), p.225-228.

Malthankar, G.V. et al., 2004. Differential Lowering by Manganese Treatment of Activities of Glycolytic and Tricarboxylic Acid (TCA) Cycle Enzymes Investigated in Neuroblastoma and Astrocytoma Cells Is Associated with Manganese-Induced Cell Death. Neurochemical Research, 29(4), p.709-717.

Minoshima, S. \& Cross, D., 2008. In vivo imaging of axonal transport using MRI: aging and Alzheimer's disease. European Journal of Nuclear Medicine and Molecular Imaging, 35 Suppl 1, p.S89-92.

Mok, S.I., Munasinghe, J.P. \& Young, W.S., 2011. Infusion-based manganese-enhanced MRI: a new imaging technique to visualize the mouse brain. Brain Structure and Function, 217(1), p.107-114.

Nairismägi, J. et al., 2006. Manganese-enhanced magnetic resonance imaging of mossy fiber plasticity in vivo. NeuroImage, 30(1), p.130-135.

Narita, K., Kawasaki, F. \& Kita, H., 1990. Mn and Mg influxes through Ca channels of motor nerve terminals are prevented by verapamil in frogs. Brain Research, 510(2), p.289-295.

Nordhøy, W. et al., 2003. Manganese ions as intracellular contrast agents: proton relaxation and calcium interactions in rat myocardium. NMR in Biomedicine, 16(2), p.82-95.

Pautler, R.G., 2004. In vivo, trans-synaptic tract-tracing utilizing manganese-enhanced magnetic resonance imaging (MEMRI). NMR in Biomedicine, 17(8), p.595-601.

Paxinos, G. \& Watson, C., 2004. The Rat Brain in Stereotaxic Coordinates - The New Coronal Set, Fifth Edition $5^{\mathrm{e}}$ éd., Academic Press.

Schmitt, C. et al., 2011. Active transport at the blood-CSF barrier contributes to manganese influx into the brain. Journal of neurochemistry, 117(4), p.747-756.

Shen, H. et al., 2007. Zinc Distribution and Expression Pattern of ZnT3 in Mouse Brain. Biological Trace Element Research, 119(2), p.166-174.

Sievers, J. et al., 1992. Development of astroglial cells in the proliferative matrices, the granule cell layer, and the hippocampal fissure of the hamster dentate gyrus. The Journal of comparative neurology, 320(1), p.1-32.

Silva, A.C. et al., 2004. Manganese-enhanced magnetic resonance imaging (MEMRI): methodological and practical considerations. NMR in Biomedicine, 17(8), p.532543. 
Sloot, W.N. \& Gramsbergen, J.-B.P., 1994. Axonal transport of manganese and its relevance to selective neurotoxicity in the rat basal ganglia. Brain Research, 657(1-2), p.124-132.

Smith, K.D.B. et al., 2007. In vivo axonal transport rates decrease in a mouse model of Alzheimer's disease. NeuroImage, 35(4), p.1401-1408.

Sole et al., 2007. A multiplatform code for the analysis of energy-dispersive X-ray fluorescence spectra. Spectrochimica Acta Part B Atomic Spectroscopy, 62(1), p.6368.

Sotak, C.H., Sharer, K. \& Koretsky, A.P., 2008. Manganese cell labeling of murine hepatocytes using manganese(III)- transferrin. Contrast Media \& Molecular Imaging, 3(3), p.95-105.

Stredrick, D.L. et al., 2004. Manganese-Induced Cytotoxicity in Dopamine-Producing Cells. NeuroToxicology, 25(4), p.543-553.

Tarohda, T. et al., 2005. Regional distributions of manganese, iron, copper, and zinc in the brains of 6-hydroxydopamine-induced parkinsonian rats. Analytical and Bioanalytical Chemistry, 383(2), p.224-234.

Tracqui, A. et al., 1995. Determination of manganese in human brain samples. Forensic Science International, 76(3), p.199-203.

Vezér, T. et al., 2007. Behavioral effects of subchronic inorganic manganese exposure in rats. American Journal of Industrial Medicine, 50(11), p.841-852.

Watanabe, T. et al., 2004. In vivo 3D MRI staining of the mouse hippocampal system using intracerebral injection of MnCl2. NeuroImage, 22(2), p.860-867.

Yasui, M., Ota, K. \& Garruto, R.M., 1995. Effects of calcium-deficient diets on manganese deposition in the central nervous system and bones of rats. Neurotoxicology, 16(3), p.511-517.

Zheng, W. \& Zhao, Q., 2001. Iron overload following manganese exposure in cultured neuronal, but not neuroglial cells. Brain Research, 897(1-2), p.175-179.

Zwingmann, C., Leibfritz, D. \& Hazell, A.S., 2004. Brain energy metabolism in a subacute rat model of manganese neurotoxicity: an ex vivo nuclear magnetic resonance study using [1-13C]glucose. Neurotoxicology, 25(4), p.573-587. 


\section{FIGURE CAPTIONS}

Fig. 1 Localization of the intra cerebral Mn injection

A. Representation of the injection site on the atlas (Paxinos \& Watson 2004).

B. Histological section after injection of indian ink (black) through the $\mathrm{Mn}$ injection tract (for control purpose) and cresyl violet staining.

Fig.2 SR-XRF Regions of interest

DG/CA3 and hippocampal fissure (HF) regions of interest were manually drawn on $\mathrm{Zn}$ element map use as a guide for anatomical correspondence with atlas map as shown in the bottom picture.

Fig. 3 MEMRI images

Coronal (top) and sagittal (bottom) MEMRI images of rat hippocampus $24 \mathrm{~h}$ after $\mathrm{Mn}$ injection: control, IP $\left(\mathrm{MnCl}_{2}, 30 \mathrm{mg} / \mathrm{Kg}\right)$ and IC $\left(\mathrm{MnCl}_{2}, 10 \mu \mathrm{L}, 50 \mathrm{mM}\right)$. We observe a contrast enhancement after $\mathrm{Mn}$ injection in several brain structures, mainly in the hippocampus. This contrast increased with IC Mn injection.

Fig. 4 MEMRI contrasts for the Control, IP and IC groups.

SNR for the CA3/DG, CA1/2 and HF ROls (mean \pm SD).

\section{Fig.5 Cellular composition of hippocampus}

Immunofluorescence of contralateral rat hippocampus (10 $\mathrm{mm}$ thickness) $24 \mathrm{~h}$ after different $\mathrm{Mn}$ injection conditions: control, IP $\left(\mathrm{MnCl}_{2}, 30 \mathrm{mg} / \mathrm{Kg}\right)$ and $\mathrm{IC}\left(\mathrm{MnCl}_{2}, 10 \mu \mathrm{L}\right.$, $50 \mathrm{~m} \mathrm{M}$ ). Nucleus is labeled by DAPI (blue), astrocytes by GFAP (red) and neurons by NeuN (green). We observe that CA3 and DG are mainly composed of neuronal cellular body while the HF is composed of astrocytes. After IC injection we have observed a hyper GFAP-density in the hilus of DG and hippocampal fissure.

Fig. 6 Map of metals distribution in hippocampus obtained by SR-XRF.

Two-dimensional elemental distribution for manganese, calcium, zinc and iron in contralateral hippocampus $24 \mathrm{~h}$ after different $\mathrm{Mn}$ injection conditions: control, IP $\left(\mathrm{MnCl}_{2}, 30 \mathrm{mg} / \mathrm{Kg}\right)$ and IC $\left(\mathrm{MnCl}_{2}, 10 \mu \mathrm{L}, 50 \mathrm{mM}\right)$. SR-XRF maps are overlaid in a brain stereotactic atlas (Paxinos \& Watson 2004). Color bar scale is in microgram of element per gram of dry weight for each element. A color bar is represented for each Mn map conditions. Corresponding MEMRI hippocampus images are represented in the left panel. Normalized sum spectrum of the CA3/DG is represented in the right panel and arrows show $\mathrm{Mn}$ peak evolution according to the injection type. We observe an increase of Mn intensity in CA3/DG according injection type and a very high load of $\mathrm{Mn}$ along the hippocampal fissure after IC Mn injection. $\mathrm{Zn}$ and $\mathrm{Fe}$ intensity were found decreased according injection type and no changes were observed for $\mathrm{Ca}$.

Fig.7 SNR (MEMRI) as a function of Mn concentration determined by SR-XRF. Each point represents one animal. The line represents a linear fit to the data. 


\section{TABLES}

\begin{tabular}{|c|c|c|c|}
\hline $\begin{array}{c}\text { Metals in } \\
\text { CA3/DG }\end{array}$ & Control $(\mu g / g)(n=3)$ & IP $(n=6)$ & IC $(n=4)$ \\
\hline $\mathbf{P}$ & $6203.7 \pm 743.2$ & $6023.0 \pm 326.3$ & $6018.8 \pm 337.6$ \\
\hline K & $5599.9 \pm 520.9$ & $5720.5 \pm 364.9$ & $5078.4 \pm 78.1 \# \#$ \\
\hline $\mathrm{Ca}$ & $163.4 \pm 104.1$ & $189.7 \pm 60.4$ & $200.6 \pm 41.2$ \\
\hline $\mathrm{Fe}$ & $36.4 \pm 13.7$ & $23.8 \pm 5.9^{*}$ & $20.6 \pm 1.9^{*}$ \\
\hline $\mathrm{Cu}$ & $2.9 \pm 0.4$ & $3.4 \pm 0.7$ & $3.4 \pm 0.8$ \\
\hline $\mathrm{Zn}$ & $55.0 \pm 8.6$ & $46.9 \pm 4.4^{*}$ & $40.5 \pm 4.6^{*}$ \\
\hline Mn & $2.5 \pm 1.6$ & $5.0 \pm 2.4$ & $25.1 \pm 9.2^{* *} \#$ \\
\hline
\end{tabular}

Tables 1. Element concentration of $\mathrm{P}, \mathrm{K}, \mathrm{Ca}, \mathrm{Fe}, \mathrm{Cu}, \mathrm{Zn}$ and $\mathrm{Mn}$ in CA3/DG in contralateral hippocampus analyzed by SR-XRF.

Concentrations are expressed in $\mu \mathrm{g}$ of element per $\mathrm{g}$ of dry weight for each injection route (Control, IP and IC). $\mathrm{N}=$ number of samples analyzed per condition.

IP and IC versus Control: ${ }^{*} p<0.05 ;{ }^{* *} p<0.01$. IC versus IP: \#\# $p<0.01$; \#\#\# $p<$ 0.001. (mean $\pm \mathrm{SD})$.

\begin{tabular}{|l|c|r|c|}
\hline $\begin{array}{c}\text { Metals in } \\
\mathrm{HF}\end{array}$ & Control $(\mu \mathrm{g} / \mathrm{g})(\mathrm{n}=3)$ & $\mathrm{IP}(\mathrm{n}=3)$ & $\mathrm{IC}(\mathrm{n}=2)$ \\
\hline $\mathbf{P}$ & $5870.0 \pm 575.4$ & $5771.0 \pm 154.7$ & $5692.0 \pm 208.2$ \\
\hline $\mathbf{K}$ & $5545.0 \pm 380.2$ & $5556.0 \pm 195.3$ & $4949.7 \pm 133.5$ \\
\hline $\mathbf{C a}$ & $147.0 \pm 102.4$ & $130.5 \pm 62.2$ & $221.7 \pm 19.3$ \\
\hline $\mathbf{F e}$ & $30.2 \pm 7.5$ & $23.5 \pm 4.0$ & $25.3 \pm 2.5$ \\
\hline $\mathbf{C u}$ & $3.5 \pm 0.7$ & $3.9 \pm 0.4$ & $3.9 \pm 0.1$ \\
\hline $\mathbf{Z n}$ & $17.3 \pm 2.9$ & $17.3 \pm 1.7$ & $15.4 \pm 1.2$ \\
\hline $\mathbf{M n}$ & $2.0 \pm 0.9$ & $3.0 \pm 2.7$ & $105.0 \pm 28.3^{\star \star} \#$ \\
\hline
\end{tabular}

Tables 2. Element concentration of $P, K, C a, F e, C u, ~ Z n$ and $\mathrm{Mn}$ in $\mathrm{HF}$ in contralateral hippocampus analyzed by SR-XRF.

Concentrations are expressed in $\mu \mathrm{g}$ of element per $\mathrm{g}$ of dry weight for each injection route (Control, IP and IC). $\mathrm{N}=$ number of samples analyzed per condition.

IC versus control: ${ }^{* *} p<0.01$; IC versus IP: \#\# $p<0.01$. (mean $\pm S D$ ). 


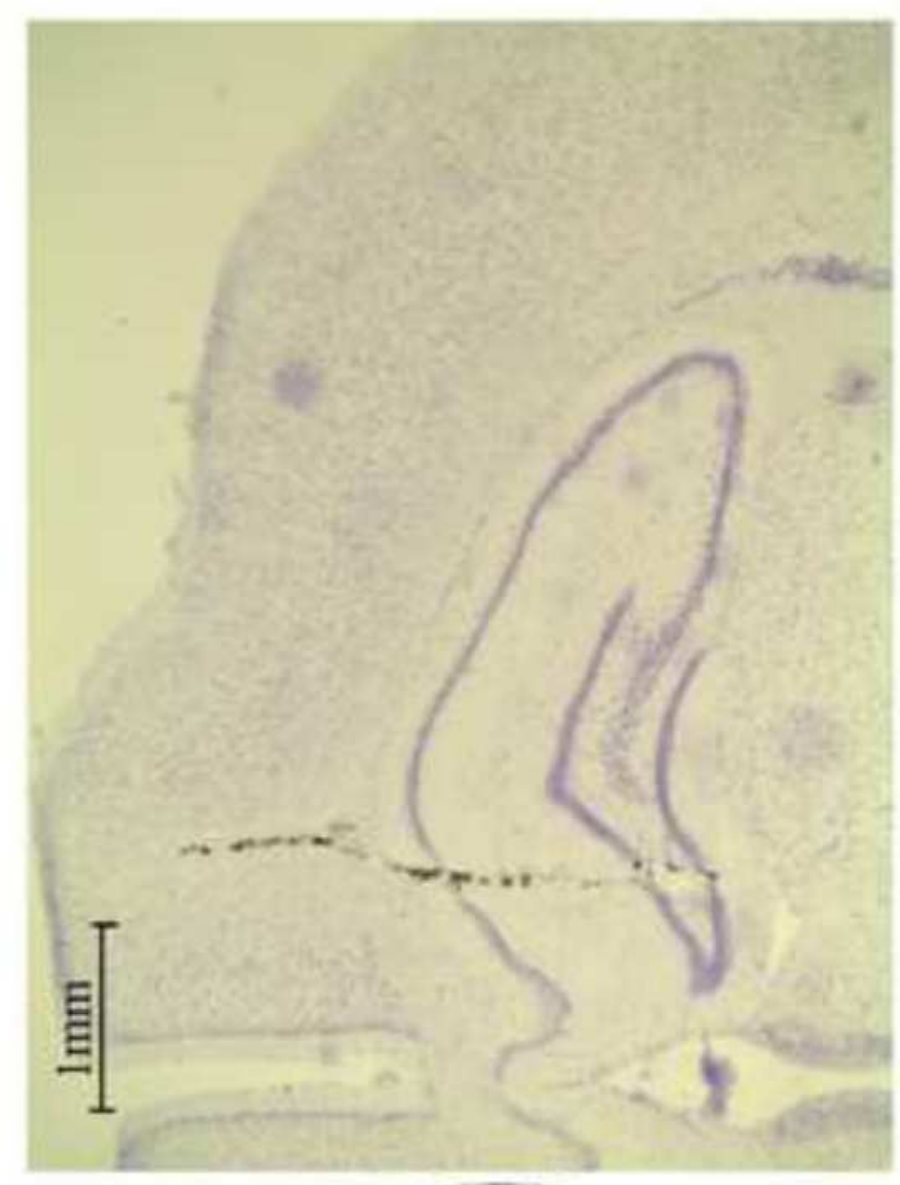

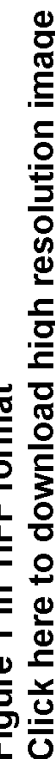

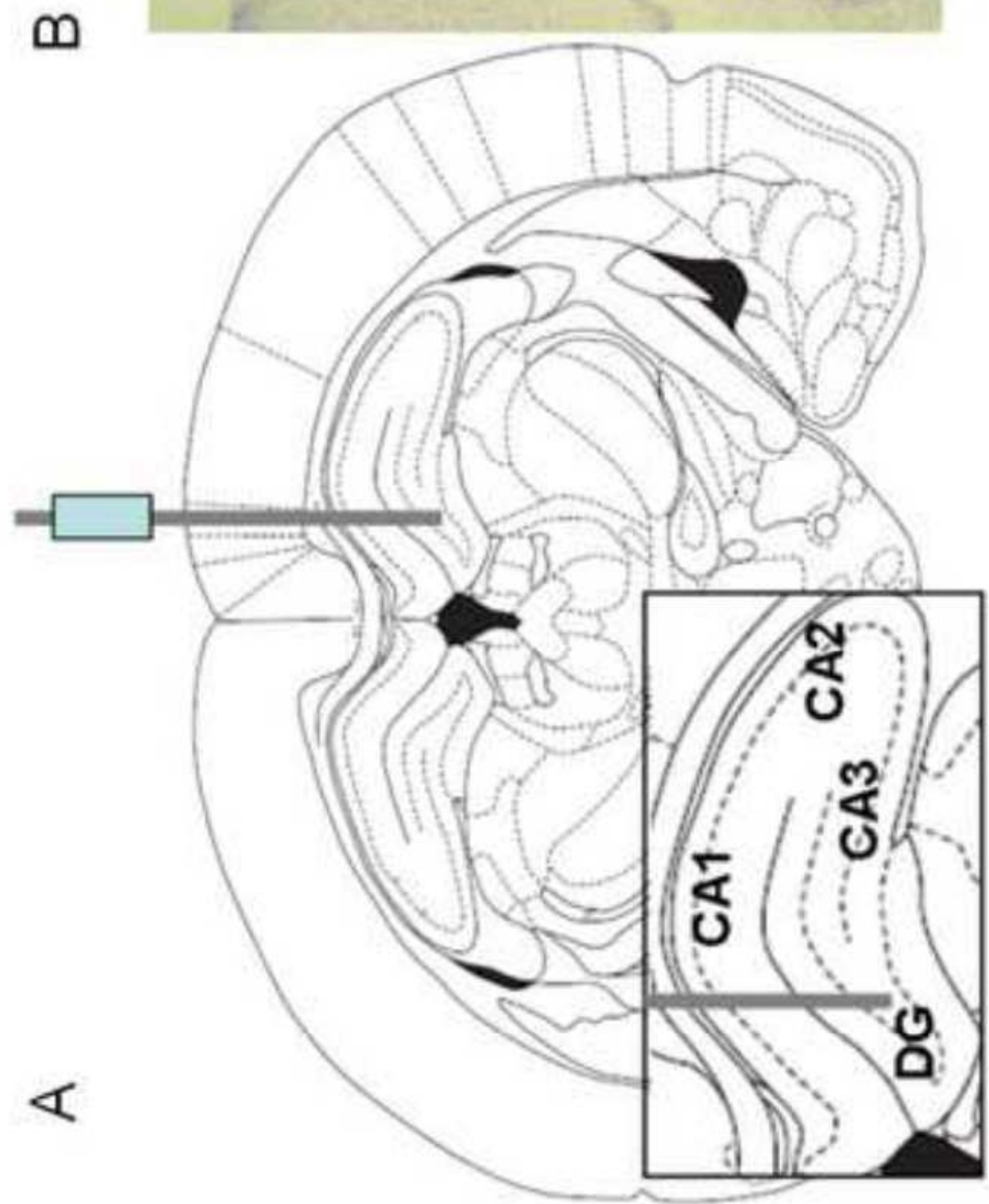



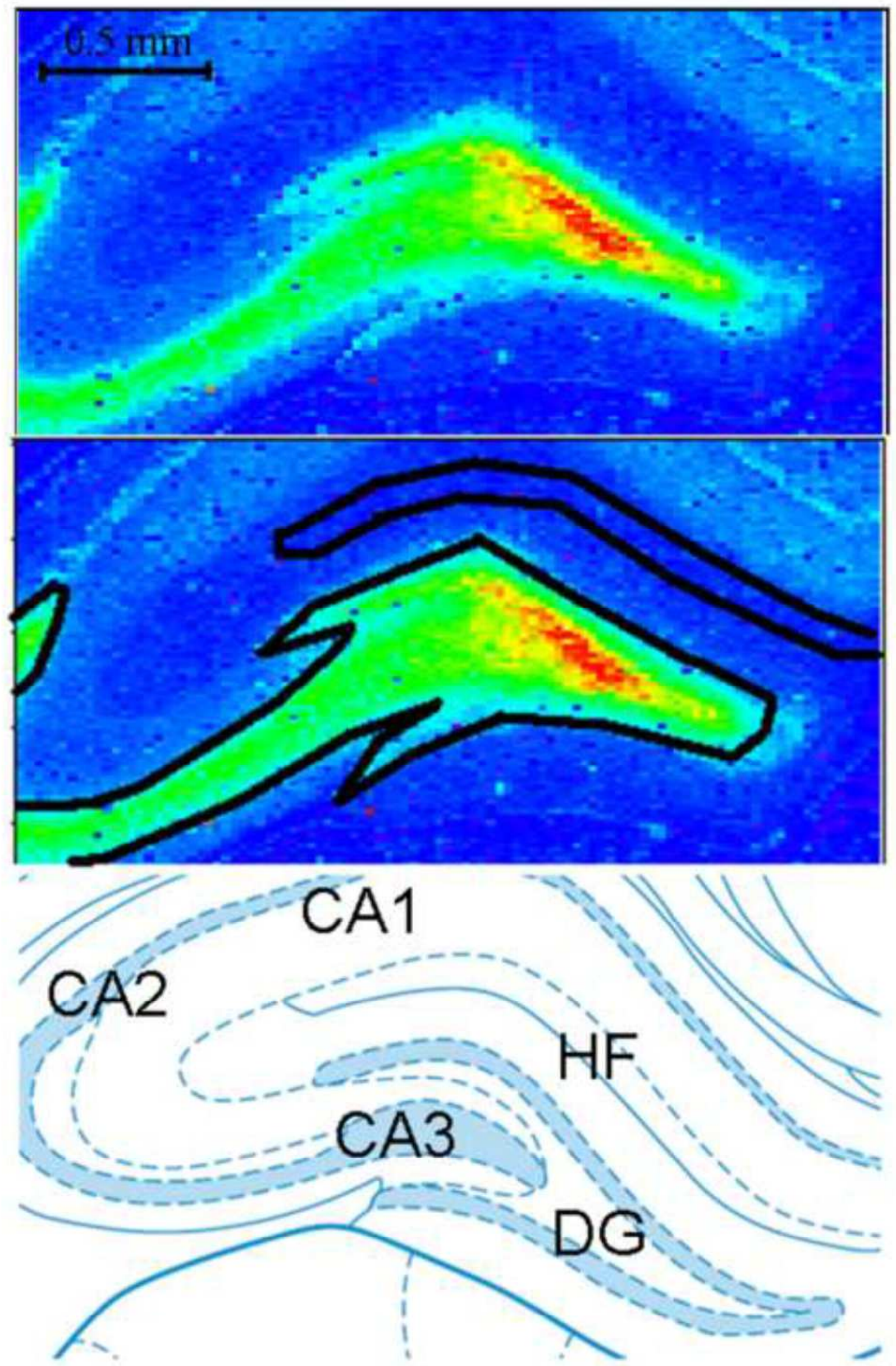


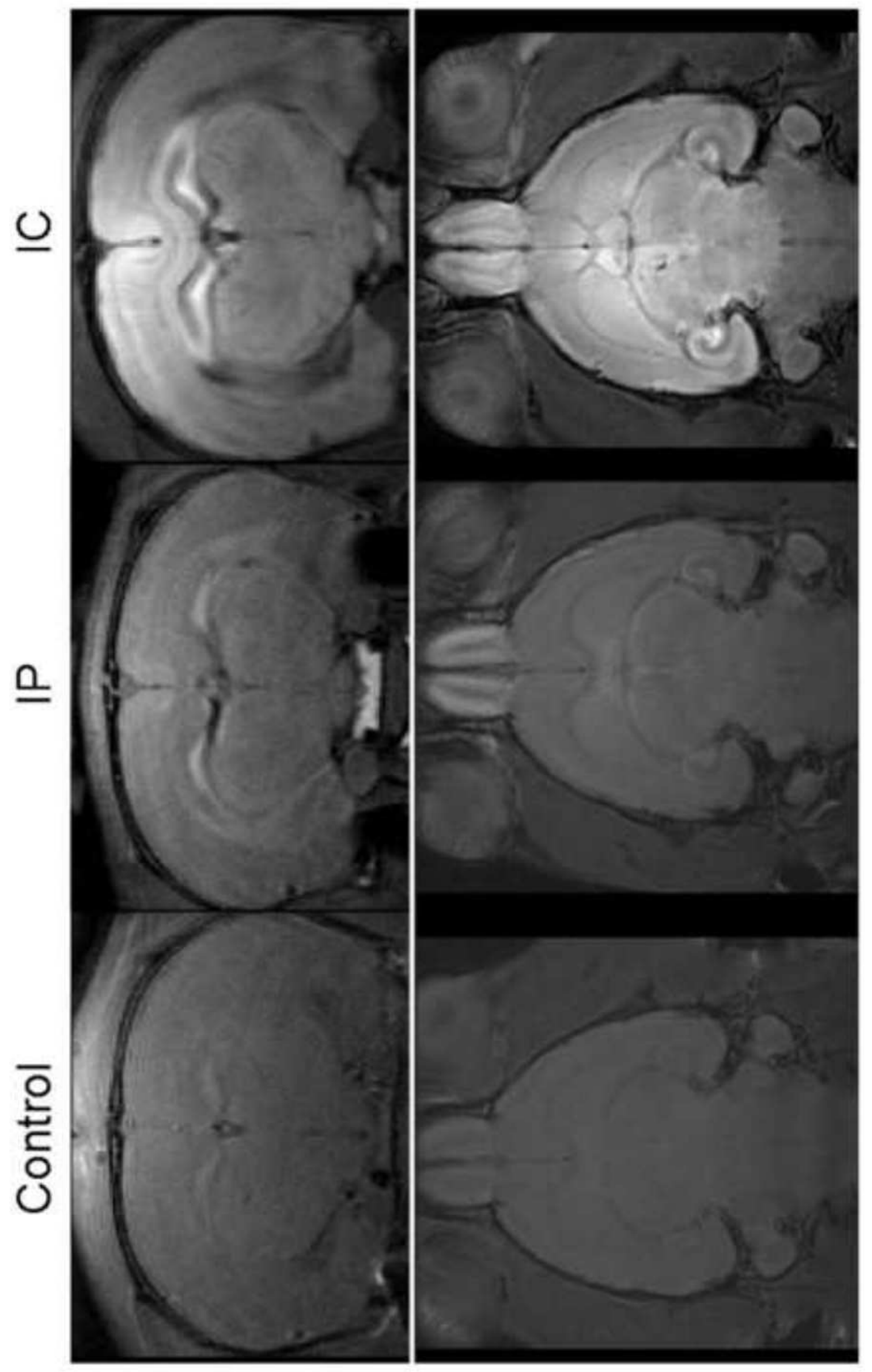

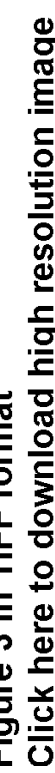



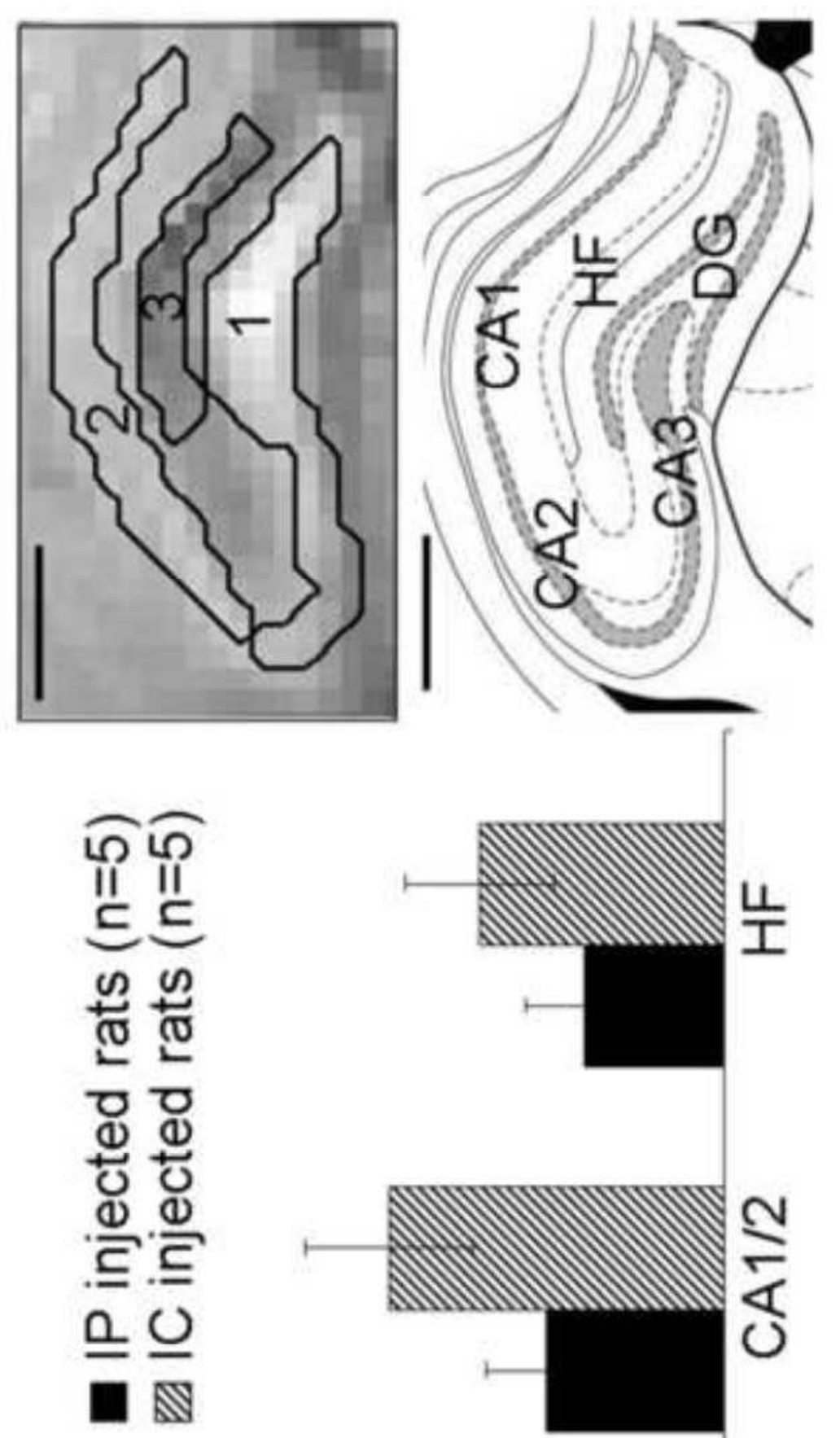

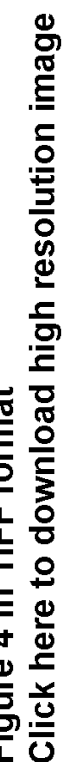
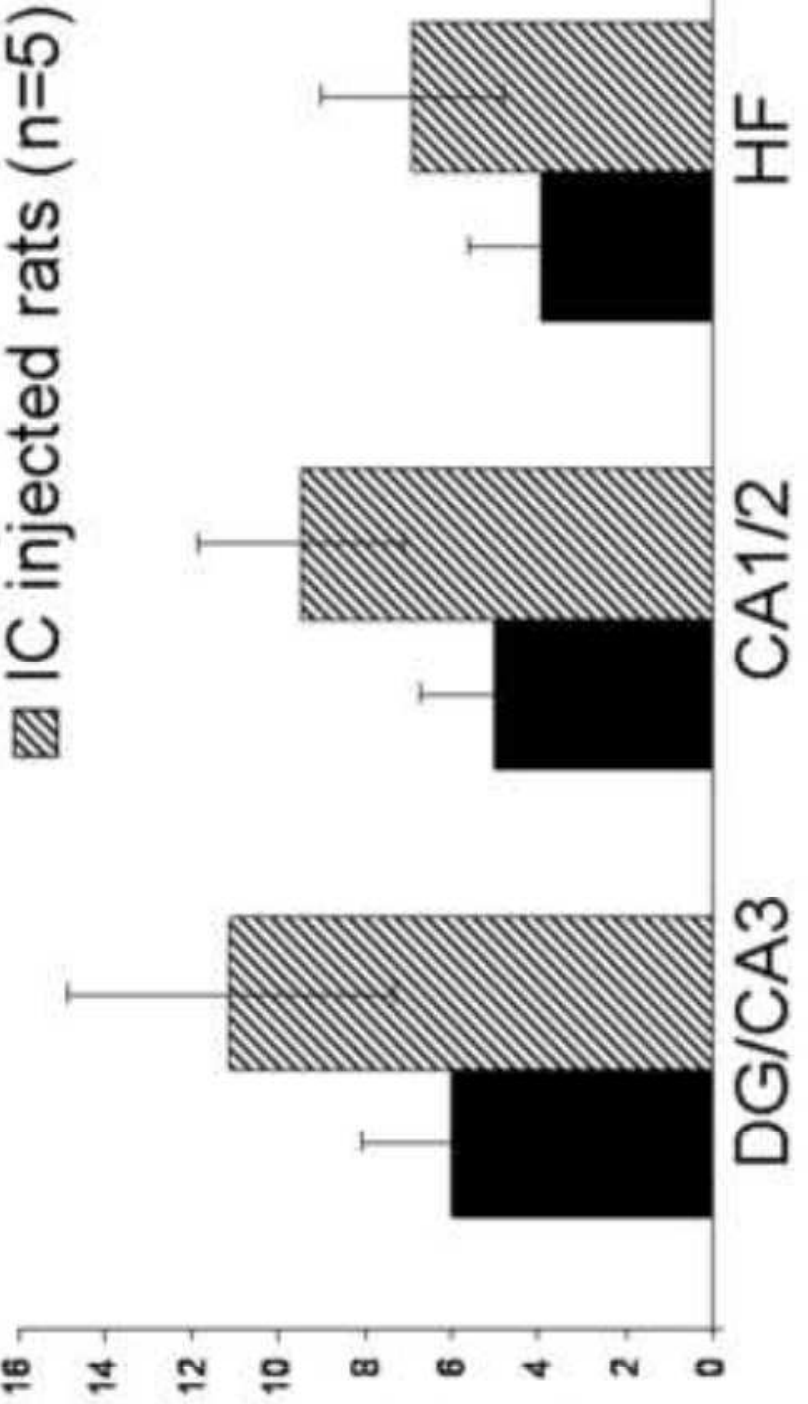

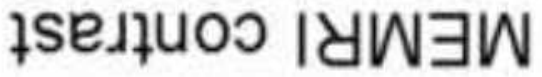


igure 5 in TIFF format

Click here to download high resolution image

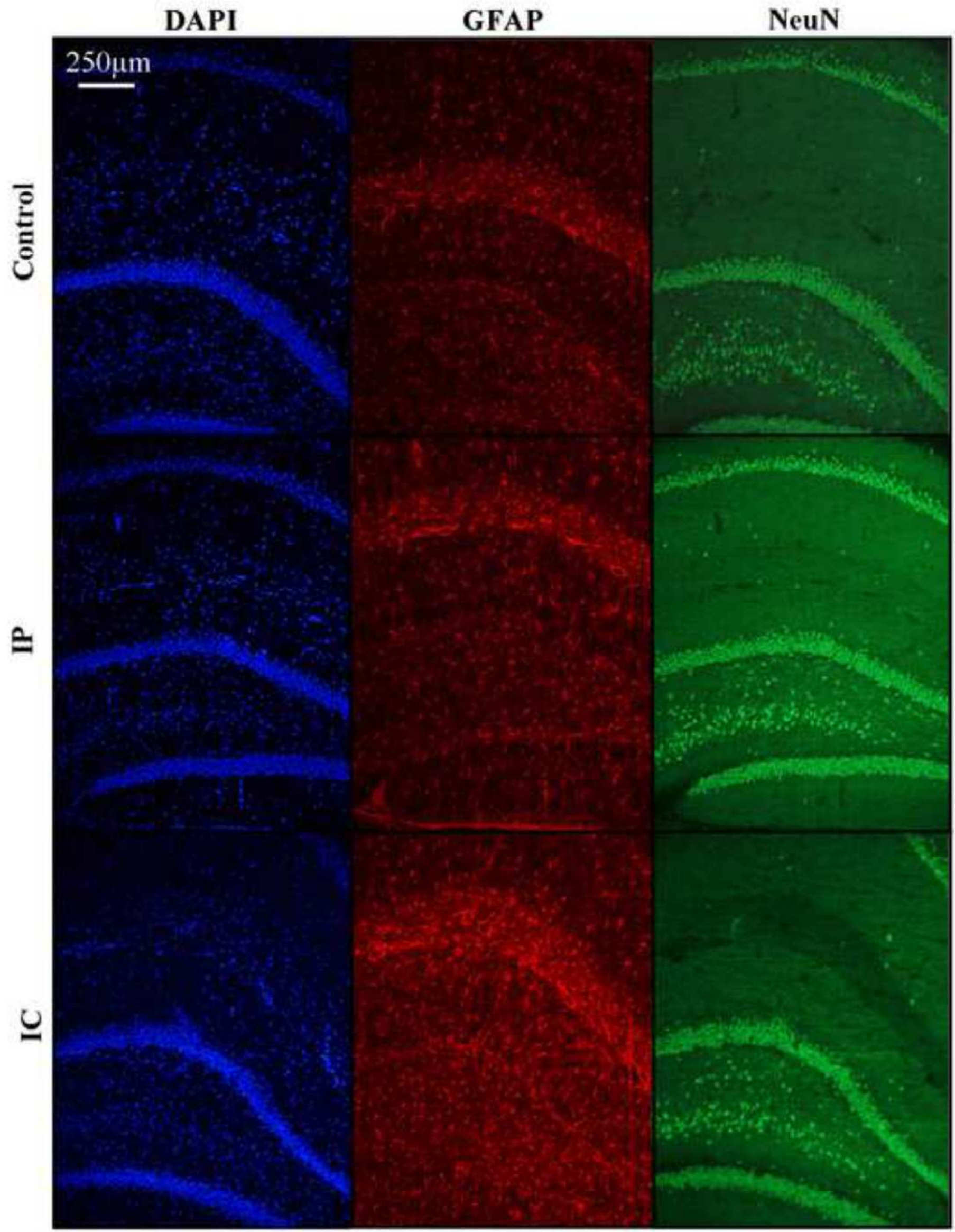




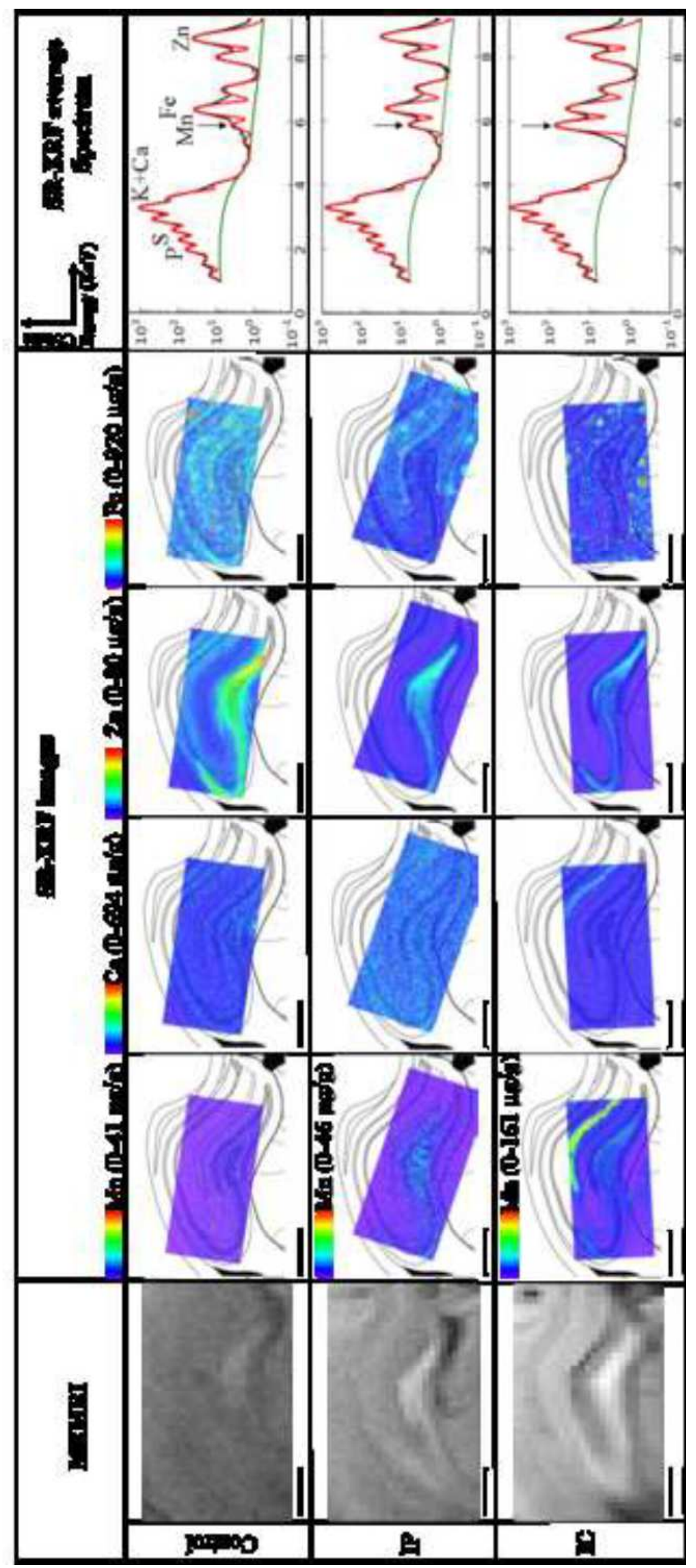




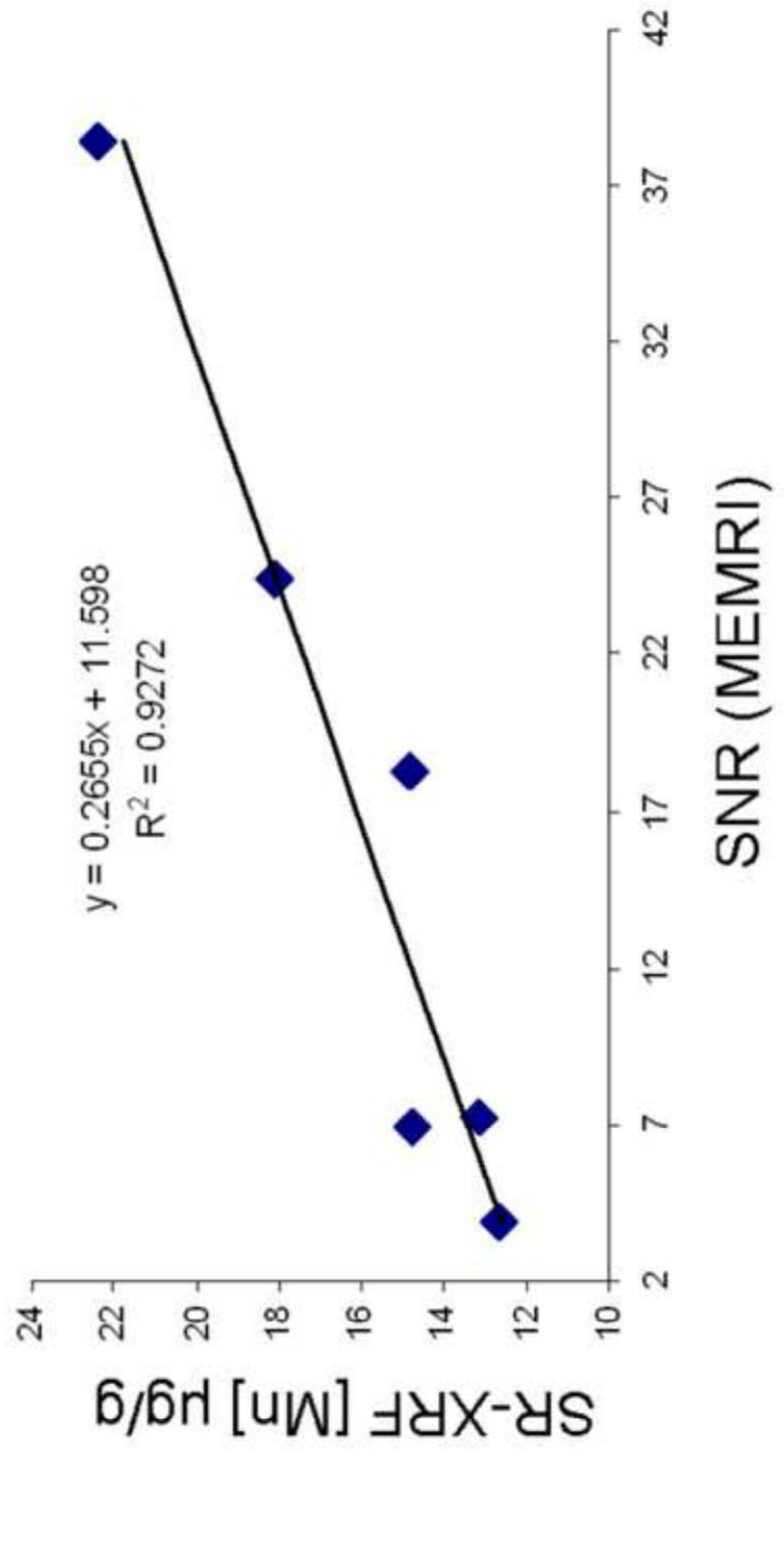

